\title{
Commentary: Is this a bridge too far?
}

\author{
Charles B. Huddleston, MD, and Andrew C. Fiore, MD
}

From the Department of Surgery, St Louis University School of Medicine, St Louis, Mo. Disclosures: Authors have nothing to disclose with regard to commercial support.

Received for publication July 18, 2019; revisions received July 18, 2019; accepted for publication July 18, 2019; available ahead of print Nov 8, 2019.

Address for reprints: Charles B. Huddleston, MD, 1465 S Grand Blvd, St Louis, MO 63104 (E-mail: Charles. huddleston@health.slu.edu).

J Thorac Cardiovasc Surg 2020;159:e225-6

$0022-5223 / \$ 36.00$

Copyright (C) 2019 by The American Association for Thoracic Surgery

https://doi.org/10.1016/j.jtcvs.2019.07.150

No one would argue against the notion that tricuspid valve regurgitation is a potentially big problem in some patients with hypoplastic left heart syndrome. It is a risk factor for early death and surgical intervention on the tricuspid valve might be necessary in up to $25 \%$ of all patients with hypoplastic left heart syndrome in the first 10 years of life. The underlying mechanisms leading to the regurgitant valve are variable and likewise a variety of repair techniques have been reported. These techniques have met with only fair success for the most part. Table 1 shows the techniques reported in the literature. Judging by the number of different methods to deal with a single problem, one can safely surmise that none of these are particularly effective in the long term. ${ }^{1}$

The procedure described by Kanno and colleagues in this issue of The Journal of Thoracic and Cardiovascular Surgery ${ }^{2}$ was derived from that described by Sughimoto and the group from Melbourne in $2015^{3}$ and by Takayama and the group from Yokohama in $1995 .{ }^{4}$ The repair in these procedures involved a bridge across a common atrioventricular valve in patients with unbalanced atrioventricular (AV) canal and single-ventricle anomalies. The bridge would function to support the common atrioventricular valve much like a ventricular septal defect patch would in a conventional repair of a complete AV canal. Both groups describe using additional techniques besides the bridge but emphasize that the key to the repair is the bridge. It is fair to say that there is some logic behind this premise and their results (albeit in a small number of patients) support their contention. However, the logic behind using this bridge across the mid portion of a tricuspid valve escapes us. The authors contend that this controlled central regurgitation, presumably the bridge, would block regurgitation at points where the leaflets might not coapt, similar to the Alfieri stitch for mitral regurgitation. It would seem that there would be some distortion of the annulus at the time of placement of this bridge and that with time that would only get worse. However, with nearly 4 years of follow-up, their single patient had neither significant tricuspid valve regurgitation nor stenosis. Amazing.

Operation Market Garden was an attempt at taking a series of bridges in The Netherlands during World War II,

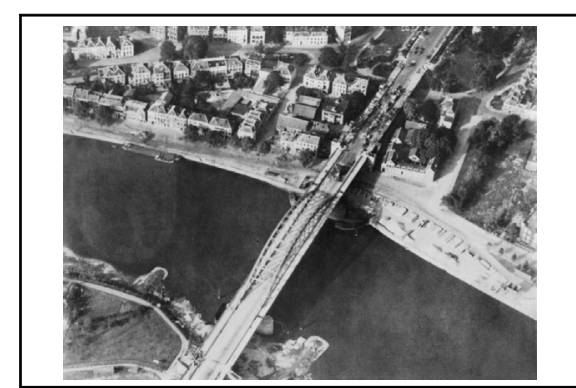

The bridge at Arnhem, The Netherlands, over the Lower Rhine-the so-called "bridge too far."

\section{Central Message}

This case report describes a unique technique that was successful in a single patient. The applicability of this technique to a larger subset of these patients is questionable.

See Article page e219.

which would allow the Allied forces to more easily cross the Rhine River and get into Germany. The bridge in Arnhem, The Netherlands was the last and critical bridge to take, but it was furthest from the Allied base and closest to a stronghold of German forces. Lieutenant General Browning warned General Montgomery of the British forces (the mastermind of the endeavor) that this was too ambitious and that the bridge in Arnhem was a bridge too far. The mission failed. ${ }^{5}$ So, is taking this bridge technique for common AV valve repair and applying it to a tricuspid valve going too far ("a bridge too far," so to speak) or is this a valuable tool to keep in our toolbox of repair techniques? Because of the marginal track record of other repair techniques on the tricuspid valve in hypoplastic left heart syndrome it is certainly reasonable to remain open to using this before throwing in the towel and replacing the valve. However, we would express caution in being too ambitious using this single case report for a repair that does not seem to have a strong anatomic or physiologic basis.

TABLE 1. Cleft closure

\begin{tabular}{l} 
Annuloplasty \\
Anterior septal leaflet commissuroplasty \\
Obliteration of the posterior leaflet \\
Partial DeVega annuloplasty \\
Papillary muscle-based repair \\
Translocation of the anterior papillary muscle \\
Relocation of the papillary muscles \\
Approximation of the papillary muscles \\
\hline
\end{tabular}




\section{References}

1. Pigula FA, Mettler B. Management of tricuspid regurgitation in patients with hypoplastic left heart syndrome. Semin Thoracic Surg. 2017;29:64-9.

2. Kanno K, Ikai A, Murata M, Sakamoto K. The interannular bridge: a new technique for the management of tricuspid regurgitation in hypoplastic left heart syndrome. J Thorac Cardiovasc Surg. 2020;159: e219-21.
3. Sughimoto K, Konstantinov IE, Brizard CP, d'Udekem Y. Polytetrafluoroethylene bridge for atrioventricular valve repair in single-ventricle palliation. J Thorac Cardiovasc Surg. 2015;149:641-3.

4. Takayama T, Nagata N, Miyairi T, Abe M, Koseni K, Yoshimura Y. Bridging annuloplasty for common atrioventricular valve regurgitation. Ann Thorac Surg. 1995;59:1003-5.

5. Ryan C. A Bridge Too Far. London: Pelican; 1970. 